\title{
Autologous Micro-fragmented Adipose Tissue in Patients With Knee Osteoarthritis: A Systematic Review and Meta-analysis
}

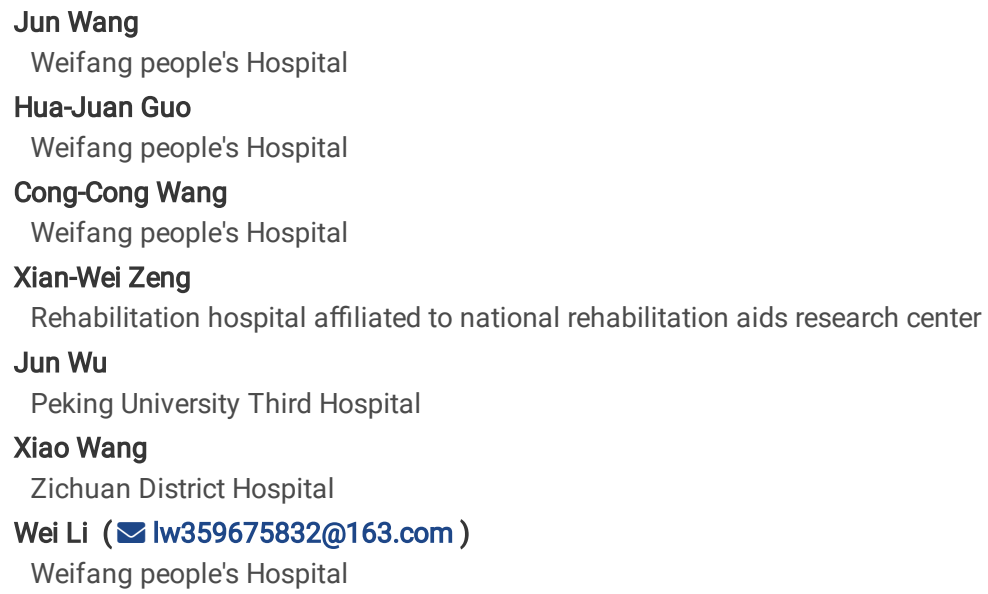




\section{Abstract}

Background: Microfragmented adipose tissue (MFAT)-containing mesenchymal stem cells (MSCs) combined with surgery is a promising strategy for the early management of knee osteoarthritis (KOA). This study aimed to explore the efficacy and safety of autologous MFAT-MSCs for the management of knee KOA.

Methods: PubMed, Embase, the Cochrane Library, and Web of Science for potentially eligible studies published up to June 2021. The primary outcome was the Knee injury and Osteoarthritis Outcome Score (KOOS). The secondary outcomes were pain assessed by visual analog scale (VAS)/numeric rating scale (NRS), quality of life (QOL) (apart from the KOOS), and adverse events (AEs). The random-effects model was used in all analyses.

Results: Eight studies (331 patients) were included. The mean differences in KOOS scores between pre-operation and post-operation (mean, $95 \% \mathrm{Cl}$ ) were 22.1 (18.7, 25.3), 19.5 (15.4, 23.6), 23.0 (19.0, 26.9), 30.8 (25.5, 35.8), and 29.9 (24.8, 35.0) for pain, symptoms, ADL, sports/recreation, and QOL, respectively. The mean differences in pain VAS between pre-operation and post-operation were -3.026 $(-3.884,-2.202)$. The mean differences in QOL between pre-operation and post-operation (mean, 95\% Cl) were -25.10 $(-29.95,-20.20), 0.039(-0.079,0.170)$, and $0.33(-0.99,1.6)$ for the Western Ontario and McMaster Universities Osteoarthritis Index (WOMAC), EQ-5D, and University of California in Los Angeles (UCLA), respectively. The use of MFAT-MSCs was not associated with bruising, bleeding, hematoma, drainage, infection, and swelling but was associated with soreness, pain, and stiffness.

Conclusions: MFAT-MSC has potential benefits for KOA while being safe. A long-term follow-up and randomized controlled trials are necessary for confirmation.

\section{Background}

Osteoarthritis (OA) is the most prevalent joint disease in the United States of America, with $38 \%-47 \%$ of people older than 60 years being affected by knee $O A(1,2)$. OA of the knee is characterized by articular cartilage loss, bone remodeling, and periarticular muscle weakness resulting in knee joint pain, swelling, deformity, and instability $(3,4)$. The causes of OA can be idiopathic or a consequence of chronic repetitive trauma or joint infection, congenital or developmental disease, crystalline deposition diseases, or autoimmune arthritis (3). Risk factors for OA include age >50 years, female sex, increasing body mass index (BMI), prior knee injury, joint laxity, occupational or recreational overuse, and family history (3-9). Over half of the persons suffering from symptomatic knee $\mathrm{OA}$ are younger than 65 years and experience significant disabilities daily (10).

The treatment goals for knee OA include relief of pain and inflammation, reduction of stiffness, and optimization of mobility, function, range of motion, and quality of life $(\mathrm{QOL})(4,11)$. The initial therapeutic options include exercise, self-management programs, acetaminophen, intra-articular corticosteroid injection, and alternative/complementary approaches $(4,11)$. For more advanced diseases, joint-preserving and joint-replacing surgeries can be considered $(4,11)$. Considering the current survival rates of primary and revision total knee arthroplasties (TKA) (12), many young patients with symptomatic knee OA are considered 'premature' for joint resurfacing surgery. Therefore, minimally invasive conservative therapies that are mainly focused on symptomatic relief seem to be more appropriate in this growing patient population.

The recruitment of autologous mesenchymal stem cells (MSCs) to manage OA symptoms is deserving of the necessary research attention in an attempt to expand the clinical toolbox of conservative, minimally invasive OA management strategies. Microfragmented adipose tissue (MFAT)-containing MSCs originate from the adipose blood vessels as pericytes and are released and primed during the extraction process through sheer stress and microfiltration of the adipose tissue $(13,14)$. MFAT-MSCs would be beneficial in providing an optimal biological environment for healing when used in conjunction with surgery (15). Their use for the treatment of knee OA has produced very encouraging results $(16,17)$.

Still, high-quality evidence of efficacy and safety is lacking. Therefore, this meta-analysis aimed to explore the efficacy and safety of autologous MFAT-MSCs for the management of knee OA. The results could help increase the focus on this strategy for performing additional studies to improve patient prognosis.

\section{Methods}

\section{Literature search}

This systematic review and meta-analysis was performed according to the Preferred Reporting Items for Systematic Reviews and Meta-Analyses (PRISMA 2020) guidelines $(18,19)$. The study was designed based on the PICOS principle $(20)$. Two investigators (** and **) independently searched PubMed, Embase, the Cochrane Library, and Web of Science for potentially eligible studies published up to June 2021, using the MeSH terms of 'Osteoarthritis', 'Osteoarthritis, Knee', and 'Autologous Micro-fragmented Fat Tissue' as well as relevant key words. The retrieved records were screened according to the eligibility criteria. The two searches were compared, and discrepancies were solved by discussion until a consensus was reached.

\section{Eligibility criteria}

The inclusion criteria were 1) population: knee OA, 2) intervention: autologous micro-fragmented adipose tissue, 3) comparison: none, 4) outcome: joint function score, QOL, joint imaging score, and adverse events (AEs), and 5) full text published in English. The exclusion criteria were 1) in vitro study, 2) in vivo study, or 3) meta-analysis, review, case report, commentary, letter to the editor, or conference abstract.

\section{Data extraction and synthesis}

Data extraction was performed by two investigators ( ${ }^{* *}$ and $* \star$ ) according to a pre-specified protocol. The extracted data included study characteristics (authors, year of publication, country where the study was performed, and study design), patient characteristics (sex, sample size, and knee OA degree), intervention characteristics (procedure, donor site for adipose tissue, and device), and outcome data. The primary outcome was the Knee injury and 
Osteoarthritis Outcome Score (KOOS), which includes five domains: 1) pain, 2) symptoms, 3) activities of daily living (ADL), 4) sports/recreation, 5) and QOL. The continuous variables in the form of mean \pm standard deviation (SD) at the last follow-up were extracted. The secondary outcomes were pain assessed by visual analog scale (VAS) or numeric rating scale (NRS), QOL (apart from the KOOS), and AEs. Disagreements in data extraction were solved by discussion until reaching a consensus. If needed, a third investigator was invited to the discussion.

\section{Quality of the evidence}

The level of evidence of all articles was assessed independently by two authors ( ${ }^{\star \star}$ and ${ }^{\star \star}$ ) according to the methodological index for non-randomized studies (MINORS) (21). Discrepancies in the assessment were resolved through discussion until a consensus was reached.

\section{Statistical analysis}

The Bayesian hierarchical (random-effects) meta-analysis model was used to analyze the scale score changes in the eligible studies. The meta-analysis was performed using a random-effects model because a high degree of between-study heterogeneity was expected. Posterior distributions were obtained after the input of prior distribution (mean $=0, S D=100)$ to the Bayesian meta-analysis. Since the scale score is a continuous variable, the effect size $(\mu)$, standard mean difference (SMD), and $95 \%$ credibility interval $(95 \% \mathrm{Crl}$ ) (i.e., the Bayesian analog of frequentist confidence intervals) for each dimension in the experimental group were estimated, as well as heterogeneity $(\tau)$. Sensitivity analysis was discussed by adjusting half-normal (HN) prior distributions, using the scale parameters 1.0. [3.4]. Bayesmeta and metafor packages in R 4.0.3 were used for data analysis. Patient satisfaction was analyzed using the command "metaprop" in R 4.0.3. Pooled forest plots were presented for all outcomes. Cochrane's Q-test and the $\mathrm{I}^{2}$ statistic were determined to assess heterogeneity, with $\mathrm{Q}$-test $\mathrm{P}<0.10$ or $\mathrm{I}^{2}>50 \%$ indicating significant heterogeneity. Two-sided P-values $<0.05$ were considered statistically significant. The possible publication bias was not assessed using funnel plots and Egger's test because the numbers of included studies were $<10$ in all analyses, in which case the funnel plots and Egger's test could yield misleading results (22).

\section{Results}

\section{Study selection}

Figure 1 presents the study selection process. The initial search identified 105 records, but 54 duplicates and 21 records marked as ineligible by automation tools were excluded before the screening. Then, 29 records were screened, and 14 were excluded. Fifteen reports were sought for retrieval, but three could not be retrieved. Twelve reports were assessed for eligibility; two were excluded because they were different reports about the same studies, and two because the outcomes did not match the preselected ones. Finally, eight studies were included.

\section{Characteristics of the included studies}

Table 1 presents the included studies. There were five prospective studies $(16,23-26)$ and three retrospective studies (27-29). Six studies were from Europe (16, $23-25,27,29)$ and two from the United Stated of America $(26,28)$. The studies included 331 patients $(17-110 /$ study).

Using the MINORS tool, two studies scored 10 points $(28,29)$, two scored 11 points $((25,27)$, three scored 12 points $((16,24,26)$, and one scored 13 points (23) (Supplementary Table S1).

\section{KOOS}

The mean differences in KOOS scores between pre-operation and post-operation (mean, 95\% Cl) were 22.1 (18.7, 25.3$), 19.5$ (15.4, 23.6$), 23.0$ (19.0, 26.9$), 30.8$ $(25.5,35.8)$, and $29.9(24.8,35.0)$ for pain, symptoms, ADL, sports/recreation, and QOL, respectively. The predictions (estimate, $95 \% \mathrm{Cl})$ were 22.1 (15.8, 28.0$)$, 19.5 (8.9, 30.1), $23.0(14.6,31.3), 30.8(20.6,40.7)$, and $30.0(18.9,40.8)$, respectively (Figure 2$)$.

\section{Pain}

The mean differences in pain scores between pre-operation and post-operation (mean, 95\% Cl) were -3.026 (-3.884, -2.202), -2.523 (-4.117, -1.032), -3.55 (-5.00, $-2.15),-4.15(-5.43,-2.89)$, and $-2.13(-4.11,-0.31)$ for VAS, VAS only, resting VAS, activity VAS, and NRS, respectively. The predictions (estimate, $95 \%$ Cl) were $-3.025(-5.564,-0.526),-2.520(-5.600,0.447),-3.55(-5.84,-1.32),-4.15(-6.23,-2.09)$, and $-2.11(-5.42,0.99)$, respectively (Figure 3).

\section{QOL}

The mean differences in QOL between pre-operation and post-operation (mean, 95\% Cl) were -25.10 (-29.95, -20.20), 0.039 (-0.079, 0.170), and 0.33 (-0.99, 1.6) for the Western Ontario and McMaster Universities Osteoarthritis Index (WOMAC), EQ-5D, and University of California in Los Angeles (UCLA), respectively. The predictions (estimate, $95 \% \mathrm{Cl})$ were $-25.10(-34.15,-16.01), 0.039(-0.201,0.292)$, and $0.33(-1.88,2.57)$, respectively (Figure 4).

\section{AEs}

The use of MFAT-MSCs was not associated with bruising, bleeding, hematoma, drainage, infection, and swelling but was associated with soreness, pain, and stiffness (Figure 5).

\section{Discussion}


MFAT-MSCs combined with surgery is a promising strategy for the early management of knee OA, but strong evidence is lacking. This meta-analysis aimed to explore the efficacy and safety of autologous MFAT-MSCs for the management of knee OA. The results suggest that MFAT-MSC has potential benefits for knee $\mathrm{OA}$ while being safe. A long-term follow-up and randomized controlled trials are necessary for confirmation.

This meta-analysis showed that using MFAT-MSCs after surgery could improve the five subscores of the KOOS, pain scores, and QOL scores. It is consistent with the fact that all wight included studies reported some degree of improvements after the use of MFAT-MSCs in their patients with knee OA (16, 23-29). Still, because all included studies have positive results, a publication bias is possible but could not be examined in the present study because of the small number of included studies (22). Nevertheless, other studies that were not eligible to the present meta-analysis support the results of the present study, suggesting that the use of MFAT-MSCs is promising for knee OA $(30,31)$. MFAT-MSCs also showed benefits in other indications, such as menopausal vaginal atrophy, perianal fistula repair, and diabetic foot (27, 32-34). MFAT-MSCs can reduce inflammation (35), increase the proliferation of cells involved in tissue repair (36), and increase tissue regeneration and repair $(30,37)$. MFAT-MSCs secrete the placental growth factor, hepatocyte growth factor, angiogenin, platelet-derived growth factor, and interleukins-13, $-3,-16$, and -27 , all acting together to enhance tissue repair (37-39). Still, the exact action mechanisms are being studied (31).

Classical management of knee OA includes corticosteroid injection, but an inflammatory flare occurs in $2 \%-25 \%$ of the cases (2). Hyaluronic acid injection carries a risk of flares and granulomatous inflammation (40). In the present meta-analysis, the meta-analysis of AEs suggests soreness, pain, and stiffness after MFAT-MSCs injection. Still, it has to be noted that these AEs were rare and only reported by a small number of studies. In addition, whether the safety profile of MFAT-MSCs is better than with other therapies remains to be investigated in comparative trials.

Four studies included outcomes that could not be pooled in the present meta-analysis. These studies showed improvements in the Tegner Lysholm Knee score, International Knee Documentation Committee (IKDC) score, and Oxford Knee Score (OKS), but not in the Emory Quality of Life (EQOL) score and delayed gadolinium-enhanced magnetic resonance imaging of cartilage (dGEMRIC) index $(23,25,28,29)$. Of course, different assessments methods have different degrees of subjectivity/objectivity and measure different outcomes. Therefore, it might highlight the need to use multiple assessment tools and to use similar tools among studies to improve the comparability of the results.

This meta-analysis has limitations. The number of included studies was small because the MFAT-MSC strategy is relatively novel. There was no comparator since the treatment is relatively new and randomized controlled trials are lacking. Heterogeneity was high because of the different patient populations, devices, and techniques.

\section{Conclusion}

In conclusion, MFAT-MSCs and surgery is probably a simple, sustainable, quick, and minimally invasive strategy for managing knee OA, with benefits and few AEs. Studies with long-term follow-up and randomized controlled trials with a large number of patients are needed to draw definitive conclusions and enlarge the indications of MFAT-MSCs.

\section{Abbreviations}

MFAT-MSCs: Microfragmented adipose tissue-containing mesenchymal stem cells, OA: osteoarthritis, KOA: knee osteoarthritis, KOOS: Knee injury and Osteoarthritis Outcome Score, VAS: visual analog scale, NRS: numeric rating scale, QOL: quality of life, AEs: adverse events, ADL: activities of daily living, WOMAC: the Western Ontario and McMaster Universities Osteoarthritis Index, EQ-5D: EuroQol Five Dimensions Questionnaire, UCLA: University of California in Los Angeles, BMI: body mass index, TKA: total knee arthroplasties, RISMA: Preferred Reporting Items for Systematic Reviews and Meta-Analyses, PICOS: Participant, Intervention, Comparison, Outcome and Study design, MeSH: Medical Subject Headings, SD: standard deviation, MINORS: methodological index for non-randomized studies, SMD: standard mean difference, Crl: credibility interval, HN: half-normal, IKDC: International Knee Documentation Committee score, OKS: Oxford Knee Score, EQOL: the Emory Quality of Life score, dGEMRIC: delayed gadolinium-enhanced magnetic resonance imaging of cartilage.

\section{Declarations}

\section{Ethics approval and consent to participate:}

Not applicable.

\section{Consent for publication}

Not applicable.

\section{Availability of data and materials}

The datasets generated and/or analysed during the current study are available from the corresponding author on reasonable request.

\section{Competing interests}

The authors declare that they have no competing interests.

\section{Funding}


This study was funded by National Natural Science Foundation of China (Grant number: No.82071470); The Natural Science Foundation of Shandong Province (Grant number: ZR2019PH026 and ZR2020MH094); and Science and technology development plan of Weifang (Grant number: 2020YX014).

This national Natural Science Foundation of China (Grant number: No.82071470) was involved in the study design, collection, analysis and interpretation of data; in the writing of the manuscript. The Natural Science Foundation of Shandong Province (Grant number: ZR2019PH026) was involved in writing of the manuscript; The science and technology development plan of Weifang (Grant number: 2020YX014) was involved in the decision to submit the manuscript for publication.

\section{Authors' contributions}

Conception and design: WL

Analysis and interpretation of the data: JW

Drafting of the article: JW

Critical revision of the article for important intellectual content: JW

Final approval of the article: WL

Provision of study materials or patients: XWZ

Statistical expertise: CCW

Obtaining of funding: XWZ

Administrative, technical, or logistic support: HJG

Collection and assembly of data: XW

JW and WL take responsibility for the integrity of the work as a whole, from inception to finished article.

\section{Acknowledgements}

Not applicable.

\section{References}

1. Zhang Y, Jordan JM. Epidemiology of osteoarthritis. Clin Geriatr Med. 2010;26(3):355-69.

2. Levy DM, Petersen KA, Scalley Vaught M, Christian DR, Cole BJ. Injections for Knee Osteoarthritis: Corticosteroids, Viscosupplementation, Platelet-Rich Plasma, and Autologous Stem Cells. Arthroscopy. 2018;34(5):1730-43.

3. Gelber AC. In the clinic. Osteoarthritis. Ann Intern Med. 2014;161(1):ITC1-16.

4. Hochberg MC, Altman RD, April KT, Benkhalti M, Guyatt G, McGowan J, et al. American College of Rheumatology 2012 recommendations for the use of nonpharmacologic and pharmacologic therapies in osteoarthritis of the hand, hip, and knee. Arthritis Care Res (Hoboken). 2012;64(4):465-74.

5. Silverwood V, Blagojevic-Bucknall M, Jinks C, Jordan JL, Protheroe J, Jordan KP. Current evidence on risk factors for knee osteoarthritis in older adults: a systematic review and meta-analysis. Osteoarthritis Cartilage. 2015;23(4):507-15.

6. Zhou ZY, Liu YK, Chen HL, Liu F. Body mass index and knee osteoarthritis risk: a dose-response meta-analysis. Obesity (Silver Spring). 2014;22(10):21805 .

7. Stehling C, Lane NE, Nevitt MC, Lynch J, McCulloch CE, Link TM. Subjects with higher physical activity levels have more severe focal knee lesions diagnosed with 3T MRI: analysis of a non-symptomatic cohort of the osteoarthritis initiative. Osteoarthritis Cartilage. 2010;18(6):776-86.

8. McAlindon TE, Wilson PW, Aliabadi P, Weissman B, Felson DT. Level of physical activity and the risk of radiographic and symptomatic knee osteoarthritis in the elderly: the Framingham study. Am J Med. 1999;106(2):151-7.

9. Harvey WF, Yang M, Cooke TD, Segal NA, Lane N, Lewis CE, et al. Association of leg-length inequality with knee osteoarthritis: a cohort study. Ann Intern Med. 2010;152(5):287-95.

10. Deshpande BR, Katz JN, Solomon DH, Yelin EH, Hunter DJ, Messier SP, et al. Number of Persons With Symptomatic Knee Osteoarthritis in the US: Impact of Race and Ethnicity, Age, Sex, and Obesity. Arthritis Care Res (Hoboken). 2016;68(12):1743-50.

11. Fernandes L, Hagen KB, Bijlsma JW, Andreassen O, Christensen P, Conaghan PG, et al. EULAR recommendations for the non-pharmacological core management of hip and knee osteoarthritis. Ann Rheum Dis. 2013;72(7):1125-35.

12. Evans JT, Walker RW, Evans JP, Blom AW, Sayers A, Whitehouse MR. How long does a knee replacement last? A systematic review and meta-analysis of case series and national registry reports with more than 15 years of follow-up. Lancet. 2019;393(10172):655-63.

13. Ahmed TA, Shousha WG, Abdo SM, Mohamed IK, El-Badri N. Human Adipose-Derived Pericytes: Biological Characterization and Reprogramming into Induced Pluripotent Stem Cells. Cell Physiol Biochem. 2020;54(2):271-86. 
14. Tremolada C, Colombo V, Ventura C. Adipose Tissue and Mesenchymal Stem Cells: State of the Art and Lipogems(R) Technology Development. Curr Stem Cell Rep. 2016;2:304-12.

15. Murphy MB, Moncivais K, Caplan Al. Mesenchymal stem cells: environmentally responsive therapeutics for regenerative medicine. Exp Mol Med. 2013;45:e54.

16. Hudetz D, Boric I, Rod E, Jelec Z, Kunovac B, Polasek O, et al. Early results of intra-articular micro-fragmented lipoaspirate treatment in patients with late stages knee osteoarthritis: a prospective study. Croatian Medical Journal. 2019;60(3):227-36.

17. Schiavone Panni A, Vasso M, Braile A, Toro G, De Cicco A, Viggiano D, et al. Preliminary results of autologous adipose-derived stem cells in early knee osteoarthritis: identification of a subpopulation with greater response. Int Orthop. 2019;43(1):7-13.

18. Prisma 2020. J Clin Epidemiol. 2021;134:A5-A6.

19. Swartz MK. PRISMA 2020: An Update. J Pediatr Health Care. 2021;35(4):351.

20. Aslam S, Emmanuel P. Formulating a researchable question: A critical step for facilitating good clinical research. Indian journal of sexually transmitted diseases and AIDS. 2010;31(1):47-50.

21. Slim K, Nini E, Forestier D, Kwiatkowski F, Panis Y, Chipponi J. Methodological index for non-randomized studies (minors): development and validation of a new instrument. ANZ journal of surgery. 2003;73(9):712-6.

22. Higgins JP, Altman DG, Gotzsche PC, Juni P, Moher D, Oxman AD, et al. The Cochrane Collaboration's tool for assessing risk of bias in randomised trials. Bmj. 2011;343:d5928.

23. Boric I, Hudetz D, Rod E, Jelec Z, Vrdoljak T, Skelin A, et al. A 24-Month Follow-Up Study of the Effect of Intra-Articular Injection of Autologous Microfragmented Fat Tissue on Proteoglycan Synthesis in Patients with Knee Osteoarthritis. Genes. 2019;10(12).

24. Genechten WV, Vuylsteke K, Martinez PR, Swinnen L, Sas K, Verdonk P. Autologous micro-fragmented adipose tissue (Mfat) to treat symptomatic knee osteoarthritis: Early outcomes of a consecutive case series. Journal of Clinical Medicine. 2021;10(11).

25. Heidari N, Noorani A, Slevin M, Cullen A, Stark L, Olgiati S, et al. Patient-Centered Outcomes of Microfragmented Adipose Tissue Treatments of Knee Osteoarthritis: An Observational, Intention-to-Treat Study at Twelve Months. Stem cells international. 2020;2020:8881405.

26. Malanga GA, Chirichella PS, Hogaboom NS, Capella T. Clinical evaluation of micro-fragmented adipose tissue as a treatment option for patients with meniscus tears with osteoarthritis: a prospective pilot study. International orthopaedics. 2020.

27. Cattaneo G, De Caro A, Napoli F, Chiapale D, Trada P, Camera A. Micro-fragmented adipose tissue injection associated with arthroscopic procedures in patients with symptomatic knee osteoarthritis. BMC musculoskeletal disorders. 2018;19(1):176.

28. Mautner K, Bowers R, Easley K, Fausel Z, Robinson R. Functional Outcomes Following Microfragmented Adipose Tissue Versus Bone Marrow Aspirate Concentrate Injections for Symptomatic Knee Osteoarthritis. Stem cells translational medicine. 2019;8(11):1149-56.

29. Russo A, Condello V, Madonna V, Guerriero M, Zorzi C. Autologous and micro-fragmented adipose tissue for the treatment of diffuse degenerative knee osteoarthritis. Journal of experimental orthopaedics. 2017;4(1):33.

30. Nava S, Sordi V, Pascucci L, Tremolada C, Ciusani E, Zeira O, et al. Long-Lasting Anti-Inflammatory Activity of Human Microfragmented Adipose Tissue. Stem cells international. 2019;2019:5901479.

31. Guo B, Sawkulycz X, Heidari N, Rogers R, Liu D, Slevin M. Characterisation of Novel Angiogenic and Potent Anti-Inflammatory Effects of Micro-Fragmented Adipose Tissue. Int J Mol Sci. 2021;22(6).

32. Laureti S, Gionchetti P, Cappelli A, Vittori L, Contedini F, Rizzello F, et al. Refractory Complex Crohn's Perianal Fistulas: A Role for Autologous Microfragmented Adipose Tissue Injection. Inflamm Bowel Dis. 2020;26(2):321-30.

33. Lonardi R, Leone N, Gennai S, Trevisi Borsari G, Covic T, Silingardi R. Autologous micro-fragmented adipose tissue for the treatment of diabetic foot minor amputations: a randomized controlled single-center clinical trial (MiFrAADiF). Stem Cell Res Ther. 2019;10(1):223.

34. Boero V, Brambilla M, Sipio E, Liverani CA, Di Martino M, Agnoli B, et al. Vulvar lichen sclerosus: A new regenerative approach through fat grafting. Gynecol Oncol. 2015;139(3):471-5.

35. Bougle A, Rocheteau P, Hivelin M, Haroche A, Briand D, Tremolada C, et al. Micro-fragmented fat injection reduces sepsis-induced acute inflammatory response in a mouse model. Br J Anaesth. 2018;121(6):1249-59.

36. Randelli P, Menon A, Ragone V, Creo P, Bergante S, Randelli F, et al. Lipogems Product Treatment Increases the Proliferation Rate of Human Tendon Stem Cells without Affecting Their Stemness and Differentiation Capability. Stem cells international. 2016;2016:4373410.

37. Vezzani B, Shaw I, Lesme H, Yong L, Khan N, Tremolada C, et al. Higher Pericyte Content and Secretory Activity of Microfragmented Human Adipose Tissue Compared to Enzymatically Derived Stromal Vascular Fraction. Stem cells translational medicine. 2018;7(12):876-86.

38. Cao Z, Ye T, Sun Y, Ji G, Shido K, Chen Y, et al. Targeting the vascular and perivascular niches as a regenerative therapy for lung and liver fibrosis. Sci Transl Med. 2017;9(405).

39. Lichtman MK, Otero-Vinas M, Falanga V. Transforming growth factor beta (TGF-beta) isoforms in wound healing and fibrosis. Wound Repair Regen. 2016;24(2):215-22.

40. Rutjes AW, Juni P, da Costa BR, Trelle S, Nuesch E, Reichenbach S. Viscosupplementation for osteoarthritis of the knee: a systematic review and metaanalysis. Ann Intern Med. 2012;157(3):180-91.

\section{Tables}

Table 1. Characteristics of the included studies 


\begin{tabular}{|c|c|c|c|c|c|c|c|c|c|c|c|}
\hline Study & Country & Study design & $\begin{array}{l}\text { Age } \\
\text { (years, } \\
\text { mean/ } \\
\text { range) }\end{array}$ & $\begin{array}{l}\text { BMl } \\
\left(\mathrm{kg} / \mathrm{m}^{2}\right)\end{array}$ & $\begin{array}{l}\text { Sex, } \\
\text { male } \\
(\%)\end{array}$ & $\begin{array}{l}\text { Sample } \\
\text { size }\end{array}$ & $\begin{array}{l}\text { KOA } \\
\text { degree }\end{array}$ & $\begin{array}{l}\text { Donor site for } \\
\text { adipose } \\
\text { tissue }\end{array}$ & Device & Procedure & $\begin{array}{l}\text { Follow- } \\
\text { up } \\
\text { (months) }\end{array}$ \\
\hline $\begin{array}{l}\text { Boric, } \\
201923\end{array}$ & Croatia & Prospective & $\begin{array}{l}69 \pm \\
12\end{array}$ & NR & $70.00 \%$ & 17 & NR & $\begin{array}{l}\text { Abdominal } \\
\text { subcutaneous }\end{array}$ & $\begin{array}{l}\text { Lipogems® } \\
\text { kit }\end{array}$ & $\begin{array}{l}\text { Intra- } \\
\text { articular, 4- } \\
15 \mathrm{~mL}\end{array}$ & 24 \\
\hline $\begin{array}{l}\text { Cattaneo, } \\
2018^{27}\end{array}$ & Italy & Retrospective & 53.8 & $27 \pm 4$ & $60.00 \%$ & 35 & NR & $\begin{array}{l}\text { Lower or the } \\
\text { lateral } \\
\text { abdomen }\end{array}$ & $\begin{array}{l}\text { Lipogems® } \\
\text { kit }\end{array}$ & $\begin{array}{l}\text { Intra- } \\
\text { articular, } \\
10 \mathrm{~cm}^{3}\end{array}$ & $\begin{array}{l}1,3,6 \\
12\end{array}$ \\
\hline $\begin{array}{l}\text { Genechten, } \\
2021^{24}\end{array}$ & Belgium & Prospective & $\begin{array}{l}54.2 \pm \\
9.1\end{array}$ & $\begin{array}{l}27.2 \pm \\
4.5\end{array}$ & $48.40 \%$ & 64 & NR & $\begin{array}{l}\text { Lumbar } \\
\text { region of the } \\
\text { abdomen }\end{array}$ & $\begin{array}{l}\text { Lipogem } \\
\text { kit }\end{array}$ & $\begin{array}{l}\text { Injected } \\
\text { under ultra- } \\
\text { sound } \\
\text { guidance } \\
\text { from the } \\
\text { lateral side } \\
\text { of the } \\
\text { index knee } \\
\text { with an 18- } \\
\text { gauge } \\
\text { needle }\end{array}$ & $\begin{array}{l}\text { Baseline, } \\
1,3,6 \\
12\end{array}$ \\
\hline $\begin{array}{l}\text { Heidari, } \\
202025\end{array}$ & Italy & Prospective & $\begin{array}{l}<50 \\
5.5 \%\end{array}$ & NR & $54.50 \%$ & 110 & $\begin{array}{l}\text { KL grade } \\
\text { of III or IV, } \\
80 \%\end{array}$ & $\begin{array}{l}\text { Lower } \\
\text { abdominal } \\
\text { area }\end{array}$ & $\begin{array}{l}\text { Lipogems } \circledR \\
\text { kit }\end{array}$ & $\begin{array}{l}\text { Single 6-8 } \\
\text { ml } \\
\text { injected } \\
\text { directly } \\
\text { into the } \\
\text { knee joint } \\
\text { under } \\
\text { ultrasound } \\
\text { guidance }\end{array}$ & NR \\
\hline $\begin{array}{l}\text { Hudetz, } \\
201916\end{array}$ & Croatia & Prospective & NR & $\begin{array}{l}<30 \\
13(65)\end{array}$ & $75.00 \%$ & 20 & III and IV & $\begin{array}{l}\text { Abdominal } \\
\text { subcutaneous }\end{array}$ & $\begin{array}{l}\text { Lipogems® } \\
\text { kit }\end{array}$ & $\begin{array}{l}\text { Intra- } \\
\text { articular, } 5 \\
\text { mL }\end{array}$ & 12 \\
\hline $\begin{array}{l}\text { Mautner, } \\
2019^{28}\end{array}$ & USA & Retrospective & $63 \pm 11$ & NR & $34.29 \%$ & 35 & NR & Abdomen & $\begin{array}{l}\text { Lipogems } ® \\
\text { kit }\end{array}$ & $\begin{array}{l}9 \text { cc of } \\
\text { MFAT was } \\
\text { injected } \\
\text { into the } \\
\text { knee joint }\end{array}$ & $\begin{array}{l}13.08 \pm \\
5.88\end{array}$ \\
\hline $\begin{array}{l}\text { Russo, } \\
201729\end{array}$ & Italy & Retrospective & $\begin{array}{l}43 \\
(35- \\
52)\end{array}$ & $\begin{array}{l}26(24- \\
28)\end{array}$ & $70.00 \%$ & 30 & NR & $\begin{array}{l}\text { Lower or } \\
\text { lateral } \\
\text { abdomen }\end{array}$ & $\begin{array}{l}\text { Lipogems }{ }_{\text {kit }} \\
\text { kit }\end{array}$ & $\begin{array}{l}\text { Intra- } \\
\text { articular, } \\
10-15 \mathrm{~cm}^{3}\end{array}$ & 12 \\
\hline
\end{tabular}

MFAT: micro-fragmented adipose tissue; NR: not reported; KOA: knee osteoarthritis

\section{Figures}


Identification of studies via databases and registers

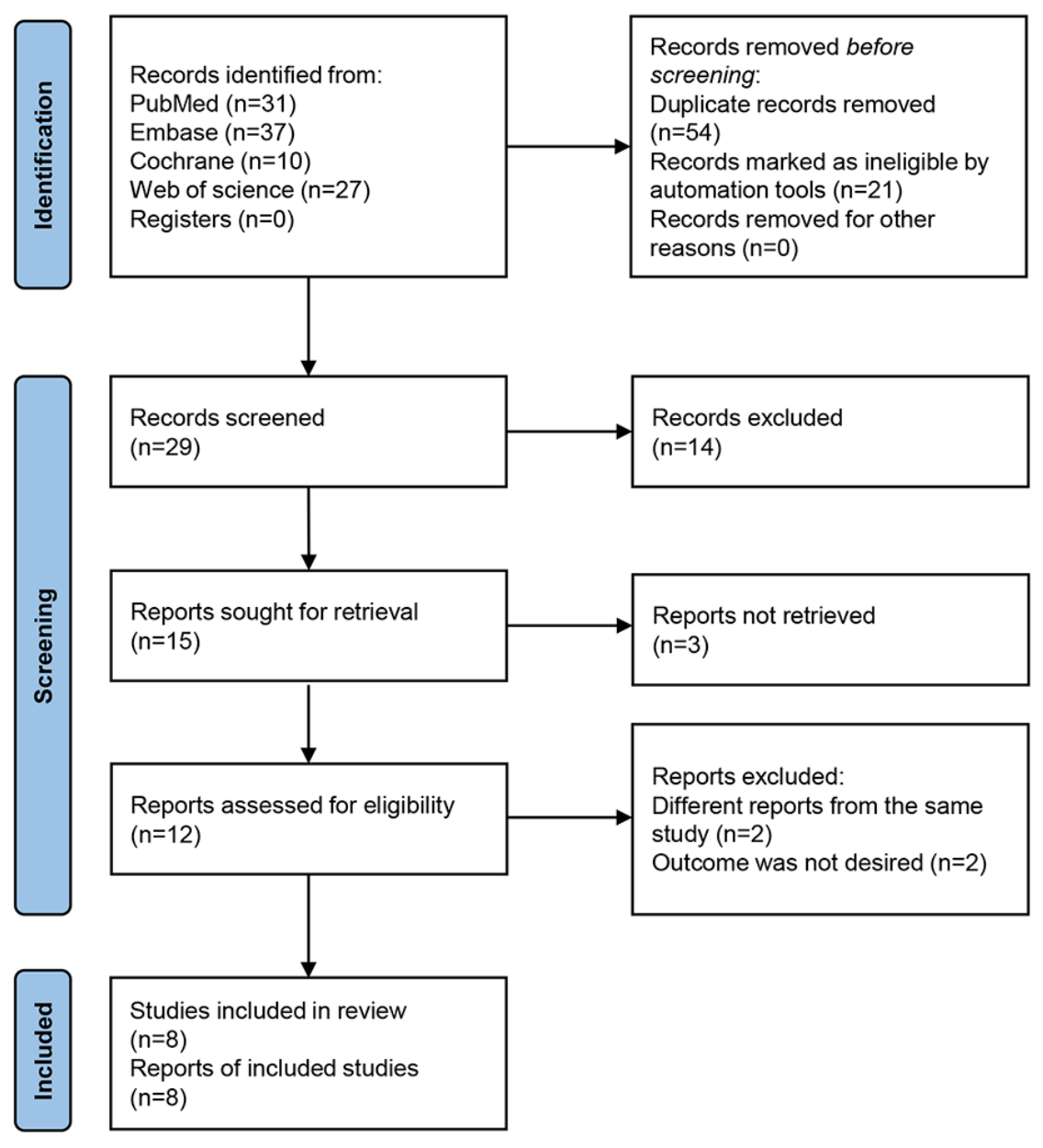

\section{Figure 1}

Flow diagram of searching and selecting studies. 

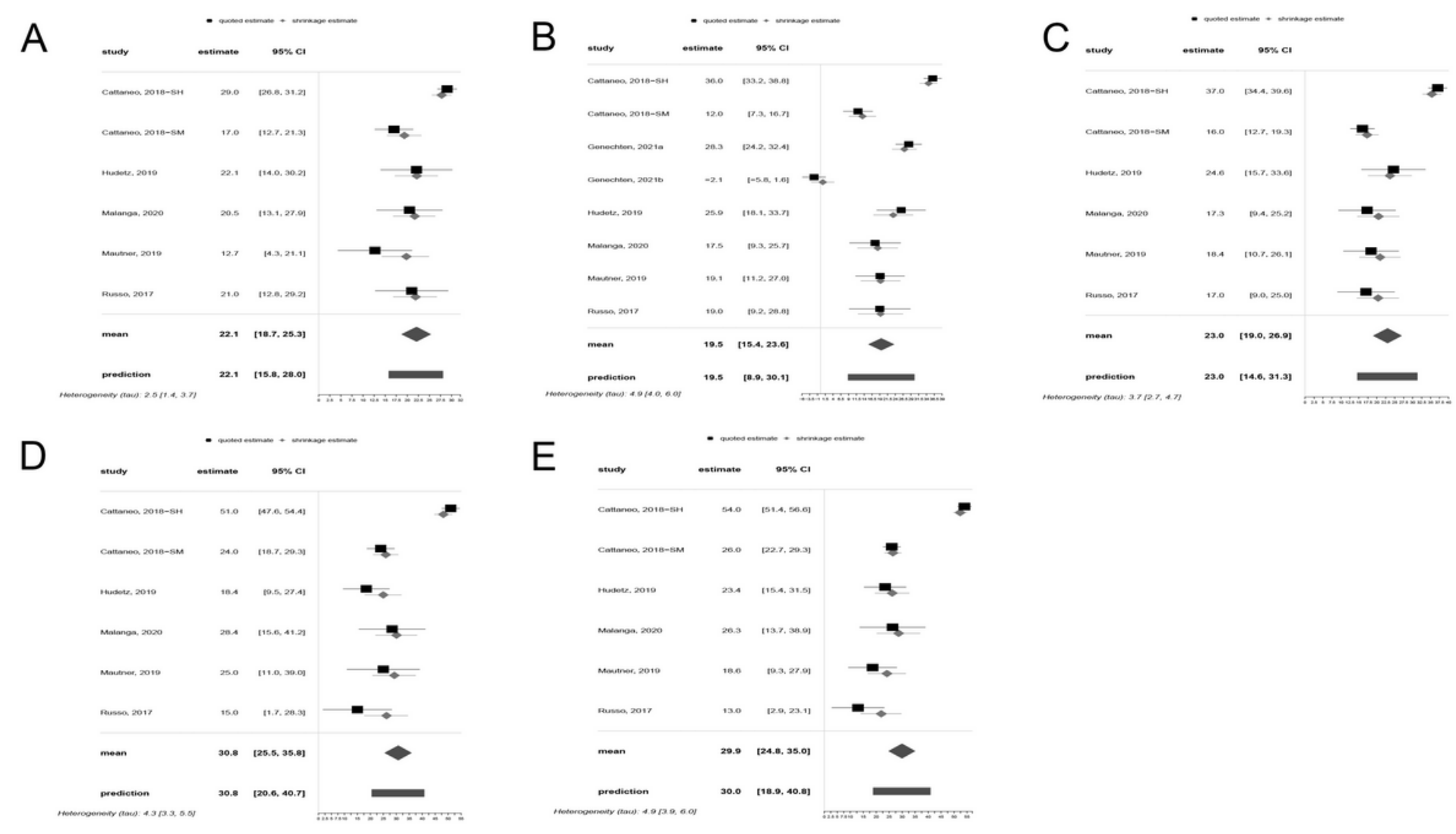

Figure 2

Forest plot of Knee Injury and Osteoarthritis Outcome Score (KOOS). (A) Pain. (B) Symptoms. (C) Activities of daily living (ADL). (D) Sport/Rec. (E) Quality of life (QOL).
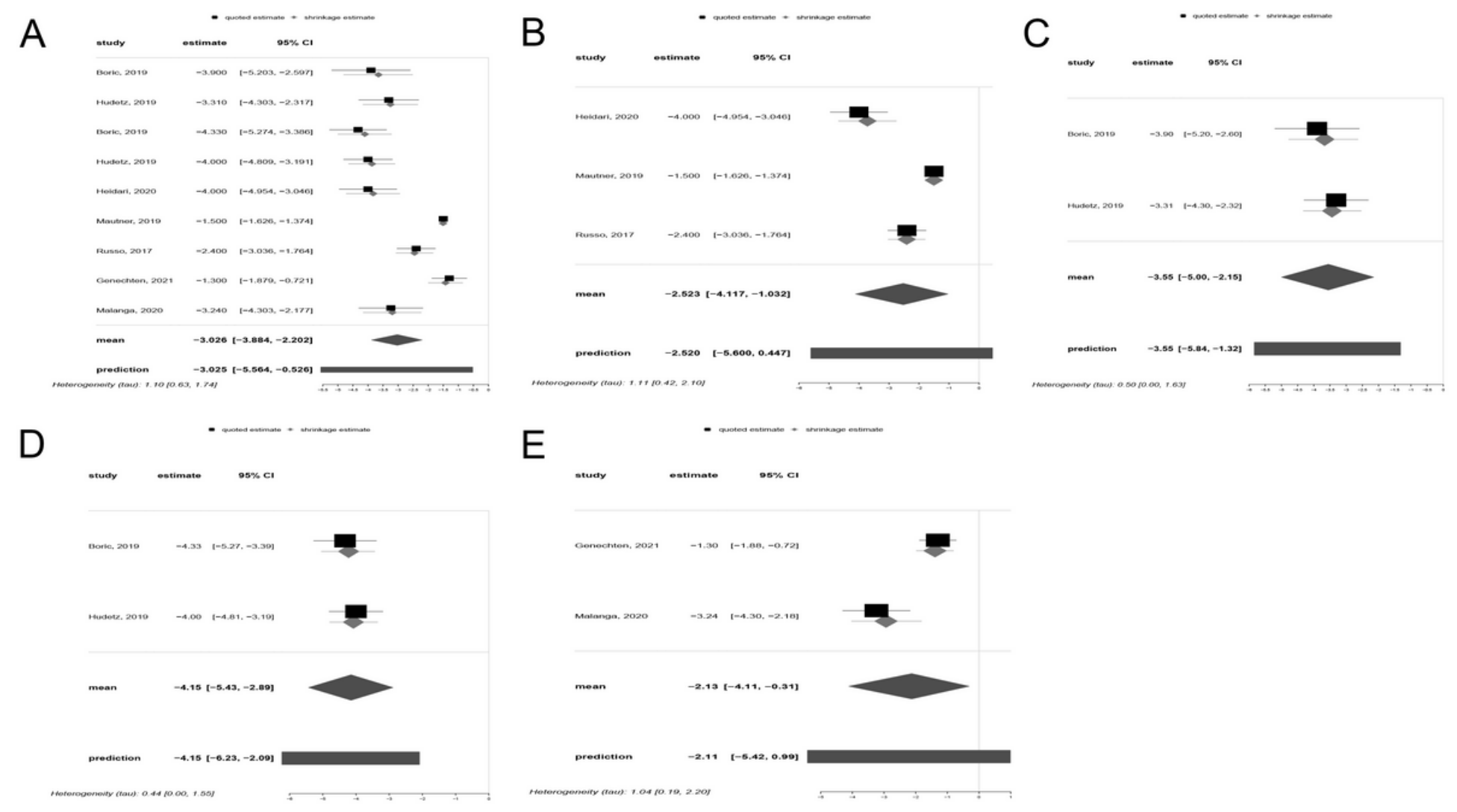

\section{E}

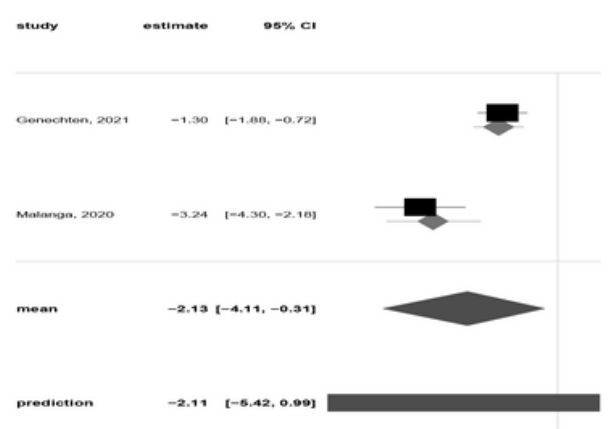


Forest plot of pain assessed. (A) visual analog scale (VAS). (B) VAS only. (C) Resting VAS. (D) Activity VAS. (E) Numeric rating scale (NRS).

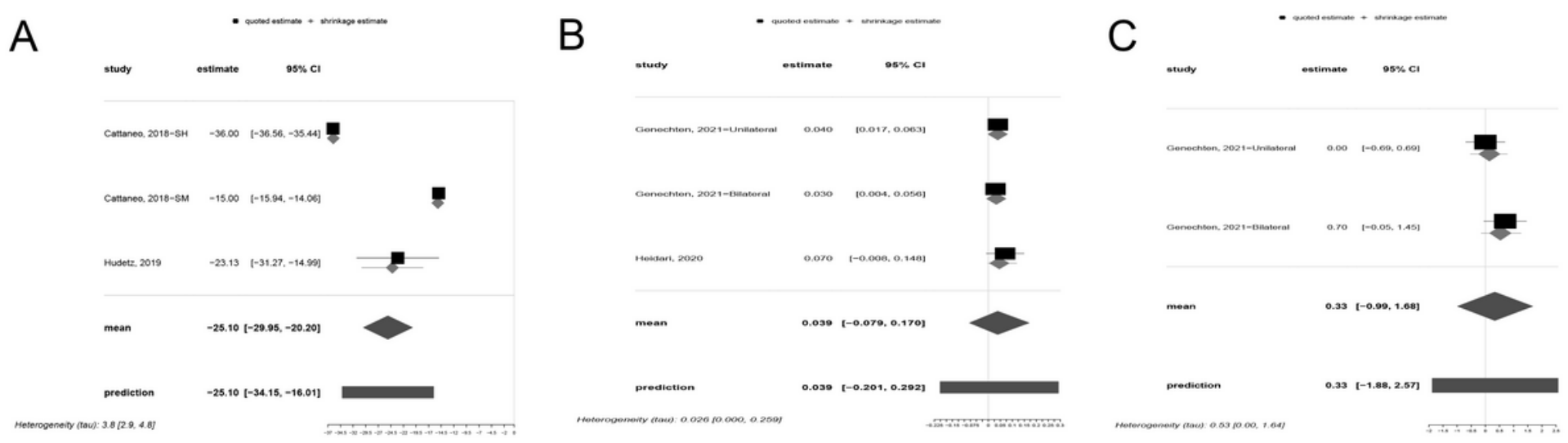

\section{Figure 4}

Forest plot of quality of life (QOL). (A) The Western Ontario and McMaster Universities Osteoarthritis Index (WOMAC). (B) EQ-5D. (C) University of California in Los Angeles (UCLA).

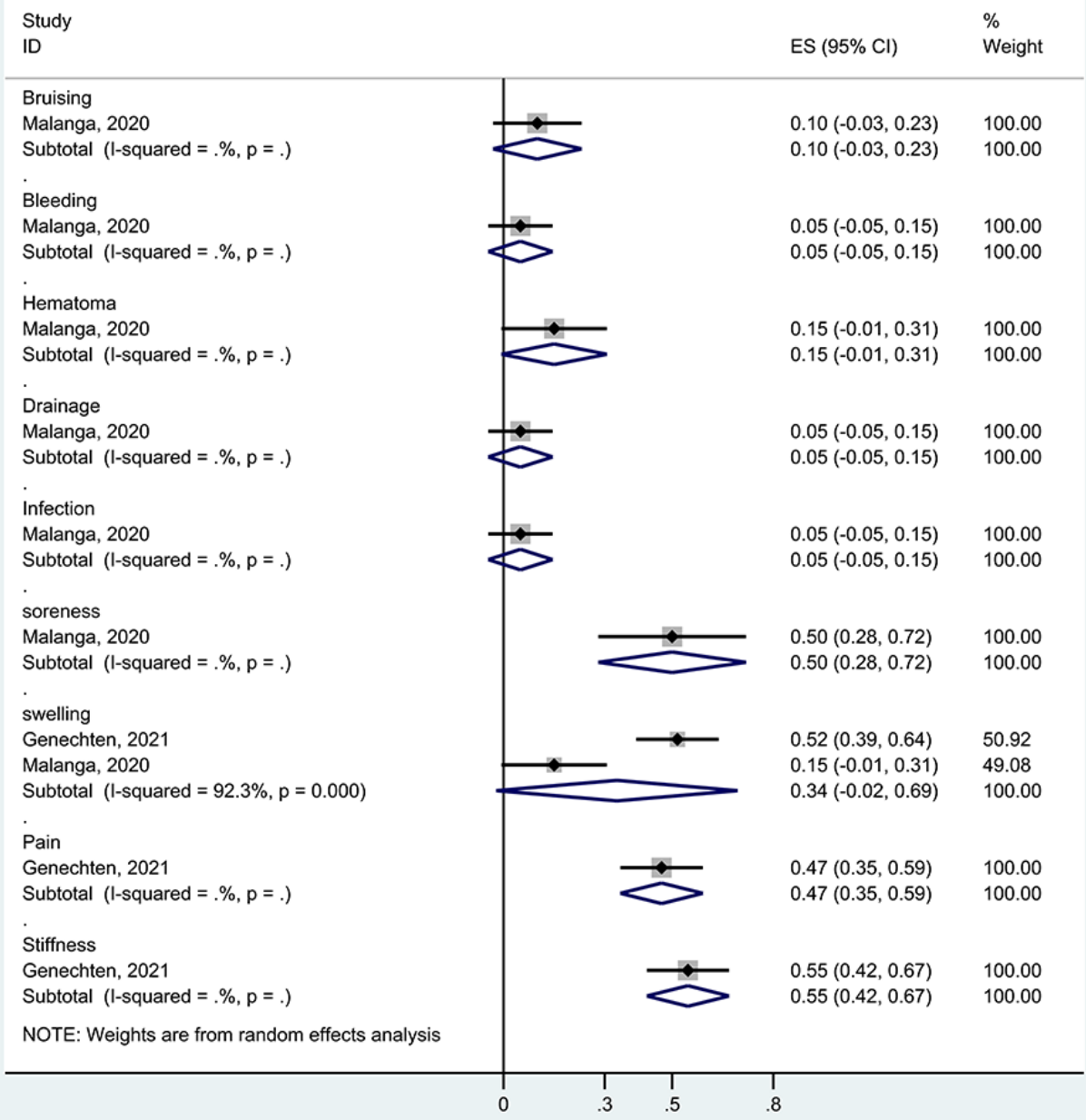

\section{Figure 5}

Forest plot of adverse events (AEs).

\section{Supplementary Files}

This is a list of supplementary files associated with this preprint. Click to download. 
- SupplementalFigureS1.tif

- SupplementaryTableS1.docx

Page 11/11 